\title{
Improved ADALINE Harmonics Extraction Algorithm for Boosting Performance of Photovoltaic Shunt Active Power Filter under Dynamic Operations
}

\author{
Muhammad Ammirrul Atiqi Mohd Zainuri ${ }^{\dagger}$, Mohd Amran Mohd Radzi*, Azura Che Soh*, \\ Norman Mariun* and Nasrudin Abd. Rahim**
}

\begin{abstract}
This paper presents improved harmonics extraction based on Adaptive Linear Neuron (ADALINE) algorithm for single phase photovoltaic (PV) shunt active power filter (SAPF). The proposed algorithm, named later as Improved ADALINE, contributes to better performance by removing cosine factor and sum of element that are considered as unnecessary features inside the existing algorithm, known as Modified Widrow-Hoff (W-H) ADALINE. A new updating technique, named as Fundamental Active Current, is introduced to replace the role of the weight factor inside the previous updating technique. For evaluation and comparison purposes, both proposed and existing algorithms have been developed. The PV SAPF with both algorithms was simulated in MATLABSimulink respectively, with and without operation or connection of PV. For hardware implementation, laboratory prototype has been developed and the proposed algorithm was programmed in TMS320F28335 DSP board. Steady state operation and three critical dynamic operations, which involve change of nonlinear loads, off-on operation between PV and SAPF, and change of irradiances, were carried out for performance evaluation. From the results and analysis, the Improved ADALINE algorithm shows the best performances with low total harmonic distortion, fast response time and high source power reduction. It performs well in both steady state and dynamic operations as compared to the Modified W-H ADALINE algorithm.
\end{abstract}

Keywords: Active power filter, Artificial neural network, Harmonics, Photovoltaic, Maximum power point tracking

\section{Introduction}

Harmonics is one of the main power quality problems in power systems that can be mitigated by using an active power filter (APF). Harmonics are sinusoidal voltages or currents, of frequencies that are multiple integer of the frequency at which the supply system is designed to operate $[1,2]$. Current harmonics may come from nonlinear load operations produced by power electronic devices and applications which are injected into the supply network through point of common coupling (PCC). In smart grid systems, these problems may arise with involvement of multiple energy sources and systems which include PV grid connected system [1-3]. To mitigate the current harmonics, shunt active power filter (SAPF) is used rather than series APF which mitigates voltage harmonics. Current harmonics are more crucial rather than voltage

$\dagger$ Corresponding Author: Dept. of Electrical and Electronic Engineering, Faculty of Engineering, Universiti Putra Malaysia, Malaysia. (ammirrulatiqi@gmail.com)

* Dept. of Electrical and Electronic Engineering, Faculty of Engineering, Universiti Putra Malaysia, Malaysia. (\{amranmr, azuracs, Norman\}@upm.edu.my)

** UM Power Energy Dedicated Advanced Centre, University of Malaya, Malaysia. (nasrudin@um.edu.my)

Received: January 2, 2016; Accepted: June 14, 2016 harmonics because in most situations, the voltage harmonics is resulted by voltage drop across the source impedance due to current harmonics inside the power system [1- 4].

Integrating SAPF with photovoltaic (PV) is one of the best options available so far. This is because the PV is much cleaner, inexhaustible, and free to harvest, making it a popular renewable energy source [5]. The availability of PV source in SAPF is not only for supplying energy to the SAPF, but also to the nonlinear loads. The higher the irradiance level, the higher the power can be obtained from the PV. This leads to lower power consumption from the grid to supply the load or to reduction of the source current However, dynamic change of the irradiance may cause inappropriate injection current produced from SAPF, and subsequently may degrade performance of the overall system.

By integrating PV with SAPF, or later known as PV SAPF, the algorithms inside its controller play their own significant roles which include harmonics extraction, DC link capacitor voltage control, synchronizer, current control, and maximum power point tracking (MPPT). For this work, the harmonics extraction algorithm is the main focus with a new approach developed which provides significant impact 
to the PV SAPF's performance. By extracting harmonics accurately to further produce the reference current (used for generating an injection current), and with fast and responsive action, should ensure the SAPF is able to compensate harmonics optimally. A good APF can successfully perform with Total harmonic Distortion (THD) of below than 5\%, which obeys IEEE Standard 5192014 (IEEE Recommended Practices and Requirements for Harmonic Control in Electric Power Systems) [6]. Apart from that, the speed of convergence of not more than $60 \mathrm{~ms}$ or 3 cycles of $50 \mathrm{~Hz}$ is required to be acceptable in many practical applications [3]. The harmonics extraction algorithms can be categorized to frequency domain, time domain and artificial intelligence techniques. In frequency domain, Discrete Fourier Transform (DFT), Recursive Discrete Fourier Transform (RDFT) and Fast Fourier Transform are widely reported [7]. Meanwhile, in time domain, synchronous fundamental d-q frame, synchronous harmonic $\mathrm{d}-\mathrm{q}$ frame and instantaneous power theory ( $\mathrm{p}-\mathrm{q}$ theory) have been explored extensively [8]. By comparing both techniques, time domain is much better as it has performed with faster convergence speed [7]. However, even though the convergence speed is considered fast, it is still questionable as possible existing of disturbance, noise and flicker due to the transformation of the input signals into $\mathrm{d}-\mathrm{q}$ or $\mathrm{p}-\mathrm{q}$ coordinates $[7,8]$. The transformation of input signals for time domain techniques mostly uses the Clarke-Park transformation with response time in around 45 to $75 \mathrm{~ms}[7,8]$.

Alternatively, artificial intelligence techniques can be considered to compensate drawbacks by both mentioned groups. Specifically, among artificial intelligence techniques, artificial neural network (ANN) is mainly focused due to its capability to perform fast and stable. The significant advantage of ANN is its ability to accurately estimate or extract the time varying fundamental component, both in terms of magnitude and phase angle, for mitigating harmonic components [9]. Adaptive Linear Neuron (ADALINE) is an ANN architecture used for functionality of APF. There is number of works on ADALINE that operates with a single linear neuron model method, which is called Widrow-Hoff (W-H) ADALINE [9-11]. Modified W-H ADALINE is an improvement from the basic W-H ADALINE algorithm as it focuses directly to extraction of the fundamental component with suitable learning rate in its updating algorithm [10]. The improvement made comes along with a couple of drawbacks. These include large size of average square error and slow learning rate due to cosine component and weight factor that may affect the algorithm's response time, and as a result, delay in compensation still exists [10]. In addition, it is still considered to have unnecessary features which do not represent the basic requirement of extracting current harmonics. The THD produced by using this particular algorithm is below than $5 \%$, with the response time of 40 ms [10].
Therefore, this paper presents an improved ADALINE algorithm for current harmonics extraction in PV SAPF. By concentrating to Modified W-H ADALINE algorithm, there are three potential major improvements have been identified which include sine and cosine coefficients, sum of elements and weight updating technique. The first improvement is by removing the cosine coefficient that exists in the Modified W-H ADALINE algorithm, in which according to symmetrical theory; this coefficient is equal to zero. The second improvement is by removing the sum of element, since the cosine coefficient is already removed. The last improvement is by changing representation of the learning factor in the updating technique from weight updating technique to fundamental active current (FAC) updating technique. The proposed improvements can significantly reduce drawbacks of the existing algorithm by minimizing later average square error and increasing convergence speed of the algorithm, which result to better THD performance and response time.

Both simulation and experimental works are carried under steady state and dynamic operations. Uniquely and comprehensively, in dynamic operation, three tests are covered such as change of nonlinear loads for SAPF without PV, off-on test between PV and SAPF, and change of irradiances to PV. These tests are crucial as whenever there is a change in the SAPF's operation, the source current also undergoes a corresponding change [9]. In addition, as no such previous works on evaluating effect of PV to effectiveness of the harmonics extraction algorithm, this work proposes a new parameter known as percentage of source power reduction which will be elaborated later. Further explanation on the single phase PV SAPF, harmonics extraction algorithm, results, and conclusion are as in sections II, III, IV, and V respectively.

\section{Single Phase Photovoltaic Shunt Active Power Filter}

\subsection{Conceptual operation}

The operation of SAPF with connection of PV array is shown in Fig. 1. Without PV, the nonlinear-load operation contains load current $I_{L}$, which is comprised of fundamental component $I_{l}$, and harmonic component $I_{H}$. Both presents within the grid source current $I_{S}$, polluting the power system. After the SAPF is connected, an injection current $I_{i n j}$ is generated which then compensates the harmonic current produced by the load, as shown below:

$$
I_{S}=I_{L}-I_{i n j}=I_{1}+I_{H}-I_{i n j}
$$

$I_{i n j}$ is generated from inverter-based configuration of SAPF, or can be denoted by $I_{i n v}$. If $I_{i n v}$ is equal to $I_{H}$, then $I_{s}$ 
will comprise $I_{l}$ only. By arranging Eq. 1 and using $I_{i n v}$, the load operates based on combination of $I_{S}$ and $I_{i n v}$, as shown below:

$$
I_{L}=I_{S}+I_{i n v}
$$

However, by connecting PV, as shown in Fig. 1, a PV current $I_{P V}$ is injected together with $I_{i n v}$, or

$$
I_{L}=I_{S}+I_{i n v}+I_{P V}
$$

Considering the same amount of current needed by the load before and after connecting the PV, $I_{S}$ should be reduced significantly from $I_{P V}$. However, as interconnection of PV and SAPF involves use of DC link capacitor, there is flow of current to charge and discharge the capacitor. Therefore, the injection current at PCC now is combination of $I_{i n v}, I_{P V}$, and capacitor charging current $I_{d c}$, or

$$
I_{i n j}=I_{i n v}+I_{P V} \pm I_{d c}
$$

Each current must be controlled in order to ensure appropriate injection is carried out by SAPF. Therefore, three main algorithms are fully considered. The harmonics

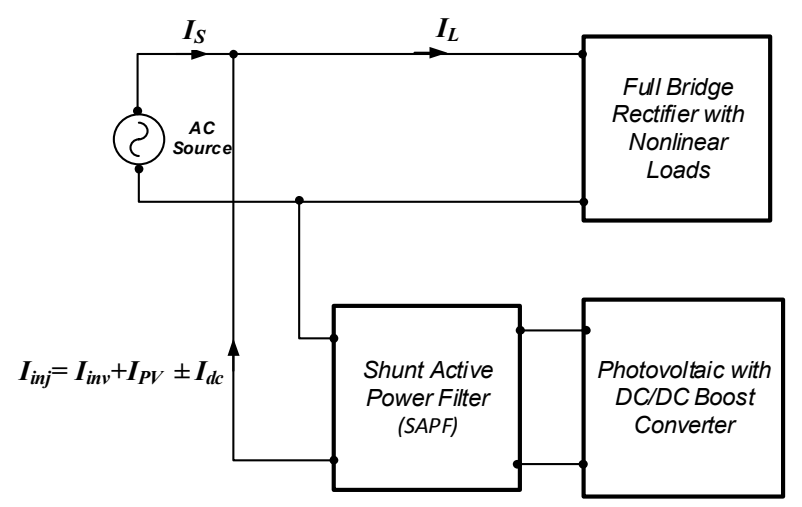

Fig. 1. Operation of SAPF with connection of PV array extraction algorithm is used to control $I_{i n v}$, maximum power point tracking (MPPT) algorithm is applied to control $I_{P V}$, and DC link capacitor voltage control algorithm is implemented to control $I_{d c}$. The generation of $I_{i n v}$, as controlled by the harmonics extraction algorithm, plays a crucial role in Eq. 4, as an inaccurate extraction will lead to improper injection current. Fast and accurate injection current will lead to better operation of SAPF. Meanwhile, $I_{P V}$ produced by the PV array is proportional to the irradiance from the sun. For $I_{d c}$, both add and minus signs show that there is possibility it is supplied from the grid (charging) or capacitor (discharging) with both directions.

\subsection{Topology and configuration}

Overall diagram of SAPF connected with PV array is shown in Fig. 2. The PV array proposed in this work is based on mono-crystalline silicon PV module with its characteristics listed in Table 1 . The PV array is connected to boost $\mathrm{DC} / \mathrm{DC}$ converter for stepping up the PV voltage. It is also a medium where maximum power point tracking (MPPT) algorithm works. The use of MPPT is crucial in any PV system as it acts to track and maintain the maximum power point of the PV array according to its irradiance. The boost DC/DC converter is connected to a full bridge inverter through DC link capacitor. To operate SAPF appropriately, its controller should cover all related strategies including MPPT algorithm, harmonics extraction algorithm, DC link capacitor voltage control algorithm,

Table 1. Characteristics of PV module (Model: SHARP NT-180U1) at $1000 \mathrm{~W} / \mathrm{m}^{2}$ irradiance.

\begin{tabular}{c|c}
\hline Parameter & Value \\
\hline Open Circuit Voltage $V_{o c}$ & $44.8 \mathrm{~V}$ \\
\hline Voltage at Maximum Power $V_{m p}$ & $35.86 \mathrm{~V}$ \\
\hline Short Circuit Current $I_{s c}$ & $5.60 \mathrm{~A}$ \\
\hline Current at Maximum Power $I_{m p}$ & $5.02 \mathrm{~A}$ \\
\hline Maximum Power $P_{\max }$ & $180 \mathrm{~W}$ \\
\hline
\end{tabular}

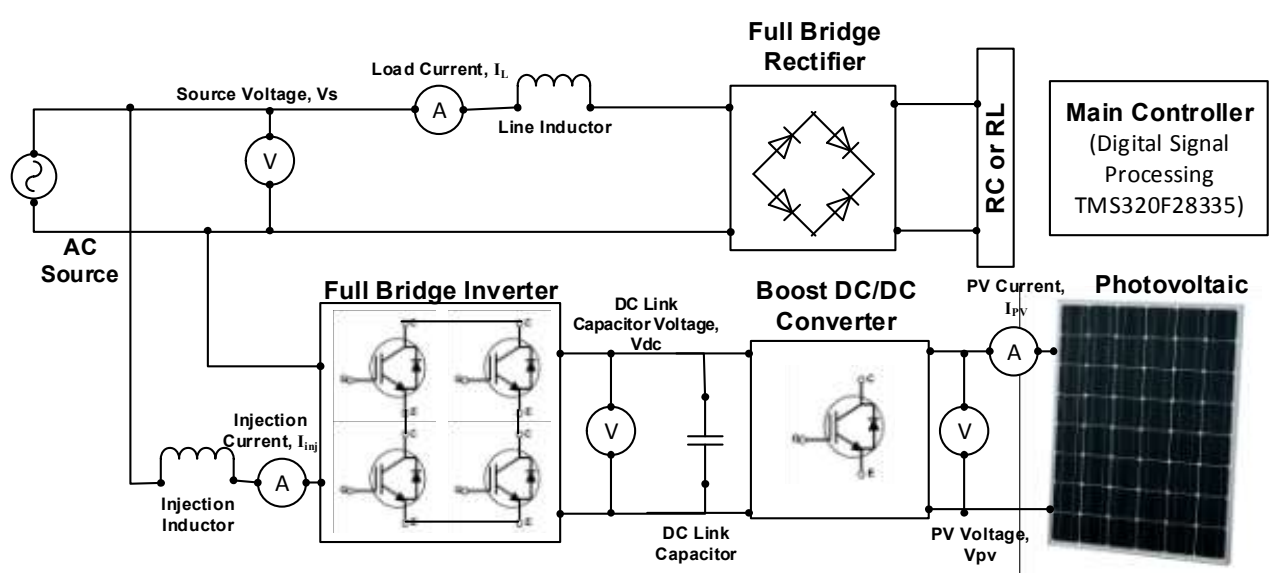

Fig. 2. Overall diagram of SAPF connected with PV array 


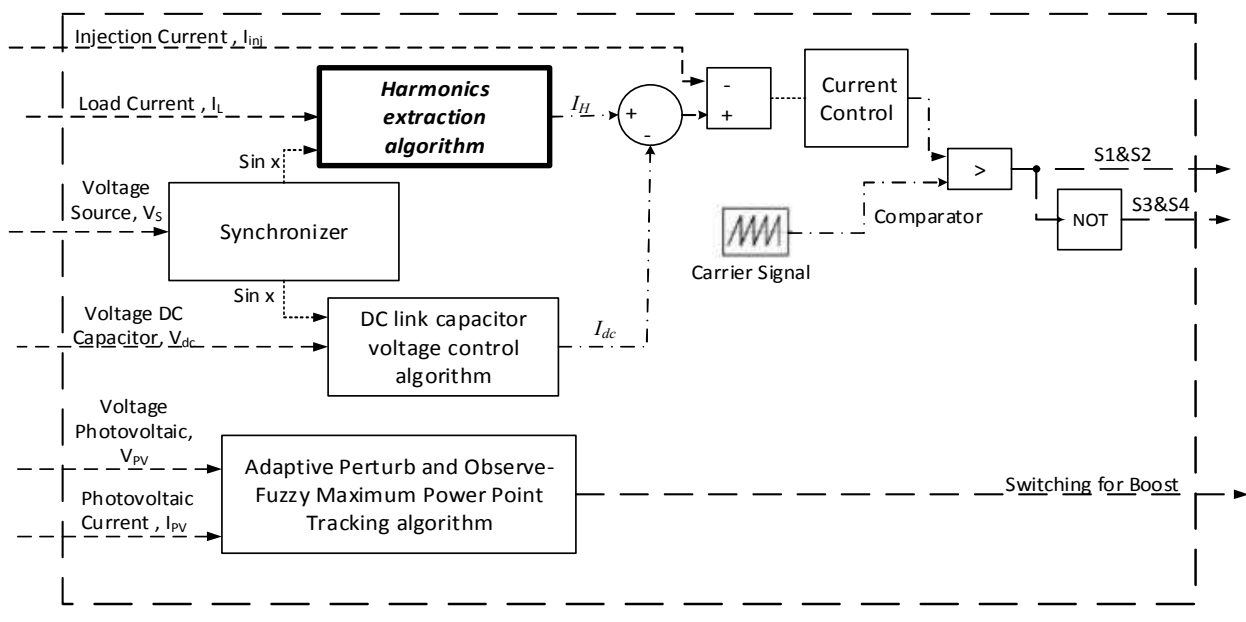

Fig. 3. Control strategies in SAPF

synchronizer, and current control algorithm, as shown in Fig. 3.

As mentioned, the highlighted algorithm in this work is the harmonics extraction algorithm. The MPPT algorithm used for this work is Adaptive Perturb and Observe (P\&O)Fuzzy, due to its better performances of tracking maximum power point [12]. For DC link capacitor voltage control algorithm, self-charging with step size error cancellation, with its outstanding features such as high accuracy and fast response time, is implemented [13]. This particular algorithm works well to control DC link capacitor voltage especially under dynamic operation. For current control algorithm, linear current control algorithm is used for this work [14]. It consists of proportional-integral (PI) technique to control steady state error of the reference current signal for generating pulse width modulation (PWM) based switching signals. The main function of synchronization algorithm is to synchronize phase of the injection current with the operating power system. For this work, the unified ADALINEs based fundamental voltage extraction algorithm is used, because of its advantages with fast, stable and accurate capability [15]. In addition, it does not need additional circuit such as zero crossing detector which brings simplicity to design of SAPF. This algorithm uses ADALINE technique, for directly extracting the fundamental voltage from the source grid. The extracted fundamental voltage in unity amplitude and sine component only, will be in phase with the voltage of the source grid. Meanwhile, the sources of harmonics are from rectifier based circuit which is connected to the grid that produces one of the highest harmonics in electrical power system $[16,17]$.

\section{Harmonics Extraction Algorithm}

\subsection{Modified widrow-hoff ADALINE algorithm}

Harmonics extraction algorithm using ADALINE applies

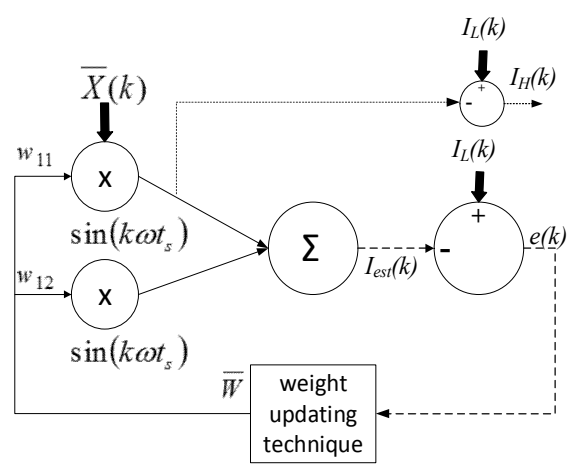

Fig. 4. Modified W-H ADALINE algorithm

the principle of sine and cosine components (periodic signal) based on the concept of estimating harmonic components that exist in the electrical system. Fundamental component and harmonic components are represented by the nonlinear load current $I_{L}$ for each sample $k$ and sampling period $t_{s}$ in digital operation with assigned fundamental frequency $\omega$ $[18,19]$. The nonlinear load current can be represented as below,

$$
I_{L}(k)=\sum_{n=1,2 . .}^{N}\left[W_{a n} \sin \left(n k \omega t_{s}\right)-W_{b n} \cos \left(n k \omega t_{s}\right)\right]
$$

where $W_{a n}$ and $W_{b n}$ are amplitudes of the sine and cosine components of the load current, and $n$ is order of the harmonic to $N$ maximum order. The main feature of this extraction algorithm is the weights updating technique where the Widrow-Hoff $(\mathrm{W}-\mathrm{H})$ method is used $[18,19]$. One of the improvements made in the Modified W-H ADALINE is it uses only the first order of harmonic component rather than $n$ number of harmonic components in normal W-H ADALINE, as shown in Fig. 4.

This algorithm has overcome the problem of conventional W-H ADALINE algorithm where number of weights $n$ must be updated which requires longer response time [10]. It only needs to update the two weights of the fundamental 
component, making it independent of number of harmonic orders. This improvement is based on the mathematical relationship of the elements being orthogonal to each other. With this modification, the iteration speed is greatly enhanced, resulting in faster estimation. However, updating only the two weights results in a large average square error $e$, thus learning rate $\alpha$ must be added as in Eq. 6 [10].

$$
\bar{W}(k+1)=\bar{W}(k)+\frac{\alpha e(k) \bar{Y}(k)}{\bar{Y}^{T}(k) \bar{Y}(k)}
$$

where $\bar{W}^{T}=\left[w_{11} w_{21}\right], \bar{Y}=\left[\begin{array}{c}\sin \left(k \omega t_{s}\right) \\ \cos \left(k \omega t_{s}\right)\end{array}\right]$ and $\alpha$ is learning rate.

Suitable learning rate is important as it will help the algorithm to optimally produce the accurate fundamental distorted current. The harmonic current $I_{H}(k)$ can be produced from load-current deduction (from load-current's fundamental sine part) as in Eq. 7 [10].

$$
I_{H}(k)=I_{L}(k)-W \sin \left(k \omega t_{s}\right)
$$

\subsection{Improved ADALINE algorithm}

Although the Modified W-H ADALINE algorithm as explained before is considered a good algorithm, it still has drawbacks that may contribute to slower performance of the harmonics extraction. It has unnecessary features which do not represent the basic requirement of extracting current harmonics. Thus, the proposed new algorithm can further be simplified and improved. Three main improvements are proposed. First is removal of the cosine coefficient with only the sine coefficient exists in the periodic signal, second is removal of sum of elements to minimize and control the large average square error $e$, and third is modification done to the weights updating algorithm. The weights updating algorithm is renamed to fundamental active current (FAC) updating algorithm for better representation.

For the first improvement, according to Eq. 7, to extract harmonic components, the main factor is to have the fundamental active current with sine coefficient. The harmonic current produced from the deduction also contains fundamental cosine part which will be compensated too. Thus, the resulted compensation can be ensured to be in phase with voltage source. In addition, as in the symmetrical theory, odd function is inversely symmetrical about the $y$-axis, where only the sine coefficient exists in odd function of periodic signal. Removing the cosine coefficient can be achieved when the operated system is in odd function. Therefore, in Eq. 5, $W_{b n}$ is directly equal to zero $\left(W_{b n}=0\right)$.

In the second improvement, since the cosine coefficient is removed, the sum of elements is automatically removed, thus reducing effect of large average square error $e$. The

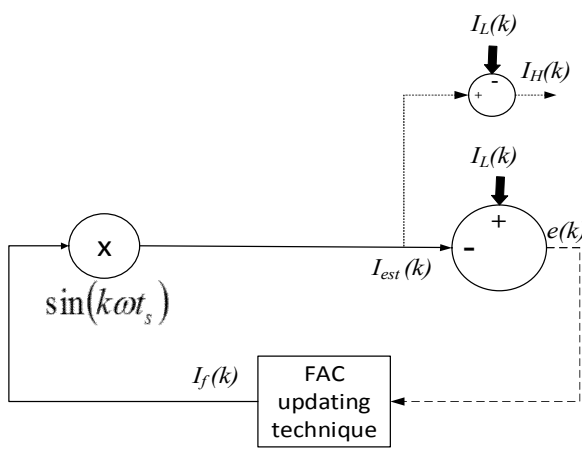

Fig. 5. Improved ADALINE algorithm

third improvement is by changing the weight updating technique. The weight factor $W$ in Eq. 6 does not give a clear representation for functionality of the SAPF. The weight factor is actually the peak value of active fundamental current before it is multiplied by sine component. To make it simpler, it is renamed as fundamental active current $I_{f}$, or

$$
I_{f}=W
$$

This newly renamed parameter will provide a better idea by directly giving information of required value for generating injection current. According to the Modified W$\mathrm{H}$ ADALINE algorithm, the weights updating equation is as below:

$$
W(k)=W(k+1)-\frac{\alpha e(k)}{\sin \left(k \omega t_{s}\right)}
$$

By replacing weight factor to fundamental active current and average square error to negative injection current, a new updating technique is formed and named as Fundamental Active Current (FAC) updating technique, where the fundamental active current is the main factor used for updating process. The new updating equation is as follow:

$$
I_{f}(k)=I_{f}(k+1)-\frac{\alpha e(k)}{\sin \left(k \omega t_{s}\right)}
$$

The final form of improved ADALINE algorithm is shown in Fig. 5. By replacing weight factor $W$ with fundamental active current $I_{f}$, as in Eq. 7, the new equation of harmonic current is

$$
I_{H}(k)=I_{L}(k)-I_{f} \sin \left(k \omega t_{s}\right)
$$

\section{Results}

As mentioned in the introduction, two types of operations were carried out to test the proposed harmonics 
extraction algorithm. The main focus is the dynamic operation, which are divided into three main tests. The first is to perform change of nonlinear loads between capacitive and inductive for SAPF without PV. The second and third tests focus on effects from integration of PV to SAPF which cover off-on operation $\left(0 \mathrm{~W} / \mathrm{m}^{2}\right.$ and $\left.600 \mathrm{~W} / \mathrm{m}^{2}\right)$ between PV and SAPF, and finally, change of irradiances between low $\left(200 \mathrm{~W} / \mathrm{m}^{2}\right)$ and high $\left(1000 \mathrm{~W} / \mathrm{m}^{2}\right)$ levels.

\subsection{Simulation results}

SAPF with PV array was developed and simulated using MATLAB/Simulink simulation software. The sampling time for this simulation was set to $6.67 \mu$ s. Table 2 lists each component used for the proposed PV SAPF. Two types of nonlinear loads were developed by using a diode H-bridge rectifier with $470 \mu \mathrm{F}$ capacitor and $50 \Omega$ resistor (capacitive load) connected in parallel as the first one, while $160-\mathrm{mH}$ inductor and $15 \Omega$ resistor (inductive load) connected in series for the second one. Duty cycle for $\mathrm{DC} / \mathrm{DC}$ boost converter was set to 0.28 . The learning rate for both harmonics extraction algorithms was set to 0.001 , as the setting approach has clearly been discussed in [10].

The first evaluation part focuses on the steady state operation. Four PV irradiance levels are covered from 0 $\mathrm{W} / \mathrm{m}^{2}$ (without $\mathrm{PV}$ ), then increased to $200 \mathrm{~W} / \mathrm{m}^{2}, 600$ $\mathrm{W} / \mathrm{m}^{2}$, and $1000 \mathrm{~W} / \mathrm{m}^{2}$. Fig. 6 shows results of implementing both harmonics extraction algorithms for inductive load,

Table 2. Parameters and components for PV SAPF

\begin{tabular}{c|c}
\hline Type & Value \\
\hline Voltage source & $230 \mathrm{~V}_{\mathrm{ac}}$ \\
\hline PV voltage & $35.86 \mathrm{~V}_{\mathrm{PV}} \times 6 \mathrm{PV}$ modules $=215.16 \mathrm{~V}_{\mathrm{PV}}$ \\
\hline DC link voltage & $400 \mathrm{~V}_{\mathrm{dc}}$ \\
\hline DC link capacitor & $4700 \mu \mathrm{F}$ \\
\hline Injection inductor & $5 \mathrm{mH}$ \\
\hline Line inductor & $1 \mathrm{mH}$ \\
\hline Boost inductor & $400 \mu \mathrm{H}$ \\
\hline Switching frequency & $25 \mathrm{kHz}$
\end{tabular}

while Fig. 7 shows results for capacitive load. From Figs. 6 and 7 , there are differences shown by the source current and the injection current from zero to high irradiances. These differences are due to additional of PV current, which directly reduces the source current and increases amount of the injection current. According to Fig. 6, THD values produced by using the proposed harmonics extraction algorithm for inductive load are $1.5 \%\left(0 \mathrm{~W} / \mathrm{m}^{2}\right)$, $1.57 \%\left(200 \mathrm{~W} / \mathrm{m}^{2}\right), 1.8 \%\left(600 \mathrm{~W} / \mathrm{m}^{2}\right)$, and $2.43 \%(1000$ $\left.\mathrm{W} / \mathrm{m}^{2}\right)$. Meanwhile, the Modified W-H ADALINE algorithm produces THD values of $2 \%\left(0 \mathrm{~W} / \mathrm{m}^{2}\right), 2.14(200$ $\left.\mathrm{W} / \mathrm{m}^{2}\right), 2.3 \%\left(600 \mathrm{~W} / \mathrm{m}^{2}\right)$, and $2.72 \%\left(1000 \mathrm{~W} / \mathrm{m}^{2}\right)$. For capacitive load, according to Fig. 7, THD values produced by using the proposed harmonics extraction algorithm are $2.29\left(0 \mathrm{~W} / \mathrm{m}^{2}\right), 2.82 \%\left(200 \mathrm{~W} / \mathrm{m}^{2}\right), 2.93 \%\left(600 \mathrm{~W} / \mathrm{m}^{2}\right)$, and $3.24 \%\left(1000 \mathrm{~W} / \mathrm{m}^{2}\right)$. Meanwhile, the Modified $\mathrm{W}-\mathrm{H}$ ADALINE algorithm produces $3.13 \%\left(0 \mathrm{~W} / \mathrm{m}^{2}\right), 3.24 \%$ $\left(200 \mathrm{~W} / \mathrm{m}^{2}\right), 3.6 \%\left(600 \mathrm{~W} / \mathrm{m}^{2}\right)$, and $3.8 \%\left(1000 \mathrm{~W} / \mathrm{m}^{2}\right)$. All obtained THDs for simulation results are summarized as in Table 3, and the Improved ADALINE algorithm has performed better than the Modified W-H ADALINE algorithm in all conditions. The decreasing amount of the source current due to operation on PV automatically increases small amount of THD values, which are still below than $5 \%$.

As mentioned, to address significant role of $\mathrm{PV}$, percentage of source power reduction is also calculated as below:

$$
P_{\%}=\frac{P_{T}-P_{S}}{P_{T}} \times 100
$$

where PT is power from the source grid during operation of SAPF without PV (as a base value) and Ps is power from the source grid when PV is connected. Table 4 shows the source power reduction and percentage of the source power reduction for both harmonics extraction algorithms using both nonlinear loads. Without PV, the source power for inductive load is $2.7 \mathrm{~kW}$ and for capacitive load is 1.8

Table 3. Simulation results for total harmonic distortion (THD) for both harmonics extraction algorithms using both nonlinear loads.

\begin{tabular}{|c|c|c|c|c|c|c|c|c|}
\hline \multirow{3}{*}{$\begin{array}{l}\text { Harmonics extraction } \\
\text { algorithms }\end{array}$} & \multicolumn{8}{|c|}{ Total harmonic distortion $(\%)$} \\
\hline & \multicolumn{4}{|c|}{ Inductive } & \multicolumn{4}{|c|}{ Capacitive } \\
\hline & $0 \mathrm{~W} / \mathrm{m}^{2}$ & $200 \mathrm{~W} / \mathrm{m}^{2}$ & $600 \mathrm{~W} / \mathrm{m}^{2}$ & $1000 \mathrm{~W} / \mathrm{m}^{2}$ & $0 \mathrm{~W} / \mathrm{m}^{2}$ & $200 \mathrm{~W} / \mathrm{m}^{2}$ & $600 \mathrm{~W} / \mathrm{m}^{2}$ & $1000 \mathrm{~W} / \mathrm{m}^{2}$ \\
\hline Improved ADALINE & 1.50 & 1.57 & 1.80 & 2.43 & 2.29 & 2.82 & 2.93 & 3.24 \\
\hline Modified W-H ADALINE & 2.00 & 2.14 & 2.30 & 2.72 & 3.13 & 3.24 & 3.60 & 3.86 \\
\hline
\end{tabular}

Table 4. Simulation results of the source power reduction and the percentage for both harmonics extraction algorithms using both nonlinear loads.

\begin{tabular}{|c|c|c|c|c|c|c|c|c|}
\hline \multirow{3}{*}{$\begin{array}{l}\text { Harmonics extraction } \\
\text { algorithms }\end{array}$} & \multicolumn{8}{|c|}{ Source Power reduction $(\mathrm{kW}) /$ Percentage of power Source reduction $(\%)$} \\
\hline & \multicolumn{4}{|c|}{ Inductive } & \multicolumn{4}{|c|}{ Capacitive } \\
\hline & $0 \mathrm{~W} / \mathrm{m}^{2}$ & $200 \mathrm{~W} / \mathrm{m}^{2}$ & $600 \mathrm{~W} / \mathrm{m}^{2}$ & $1000 \mathrm{~W} / \mathrm{m}^{2}$ & $0 \mathrm{~W} / \mathrm{m}^{2}$ & $200 \mathrm{~W} / \mathrm{m}^{2}$ & $600 \mathrm{~W} / \mathrm{m}^{2}$ & $1000 \mathrm{~W} / \mathrm{m}^{2}$ \\
\hline Improved ADALINE & $0.00 / 0.00$ & $0.14 / 5.18$ & $0.41 / 15.18$ & $0.64 / 23.71$ & $0.00 / 0.00$ & $0.09 / 5.00$ & $0.25 / 13.88$ & $0.40 / 22.22$ \\
\hline Modified W-H ADALINE & $0.00 / 0.00$ & $0.12 / 4.44$ & $0.39 / 14.44$ & $0.61 / 22.59$ & $0.00 / 0.00$ & $0.07 / 3.88$ & $0.24 / 13.33$ & $0.38 / 16.67$ \\
\hline
\end{tabular}




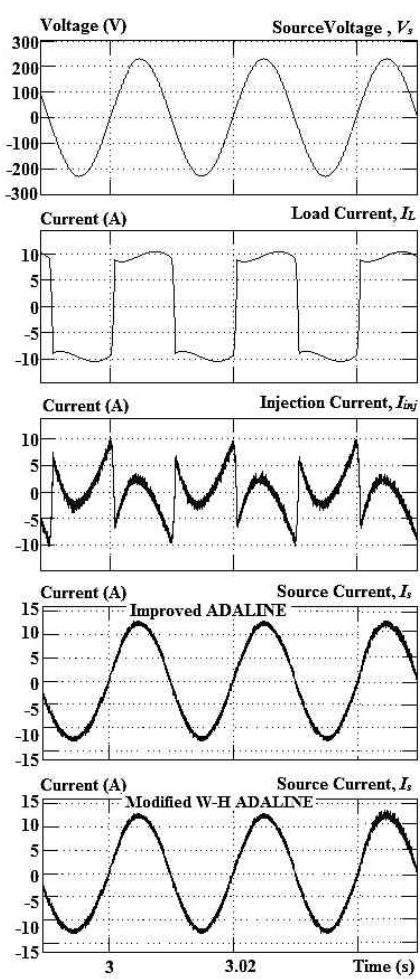

(a)
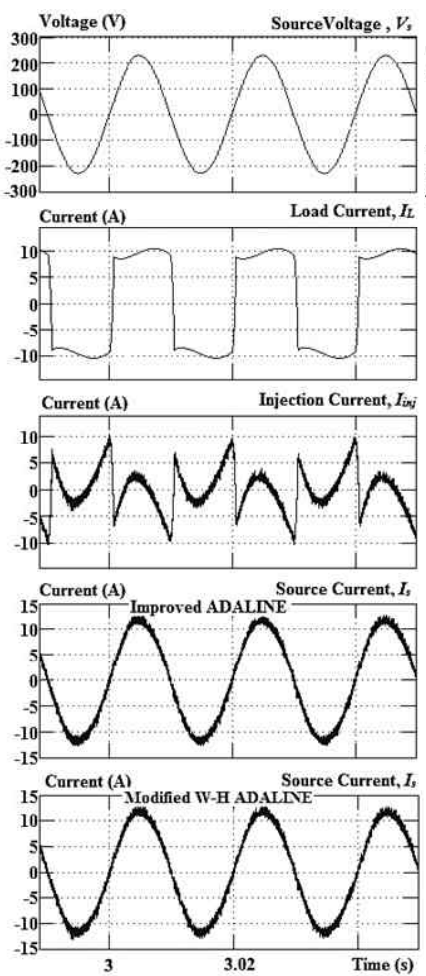

(b)

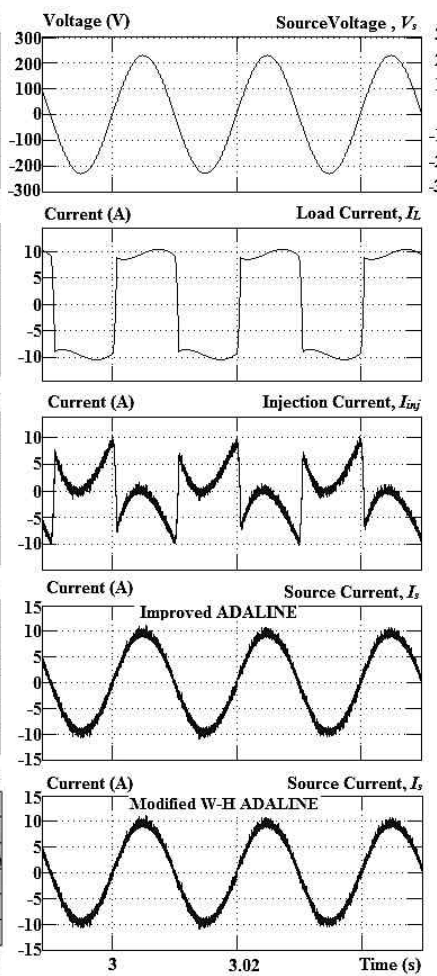

(c)

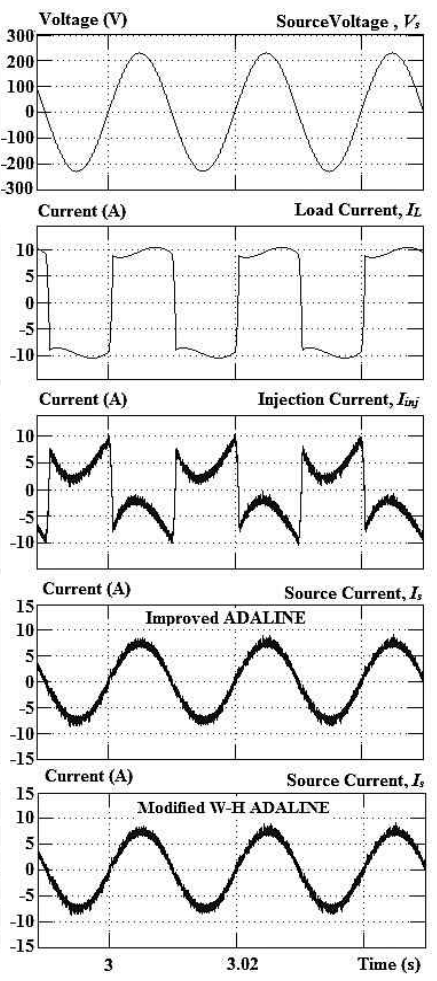

(d)

Fig. 6. Simulation results of steady state operation using inductive load under different irradiance levels at (a) $0 \mathrm{~W} / \mathrm{m}^{2},(\mathrm{~b})$ $200 \mathrm{~W} / \mathrm{m}^{2}$, (c) $600 \mathrm{~W} / \mathrm{m}^{2}$, and (d) $1000 \mathrm{~W} / \mathrm{m}^{2}$
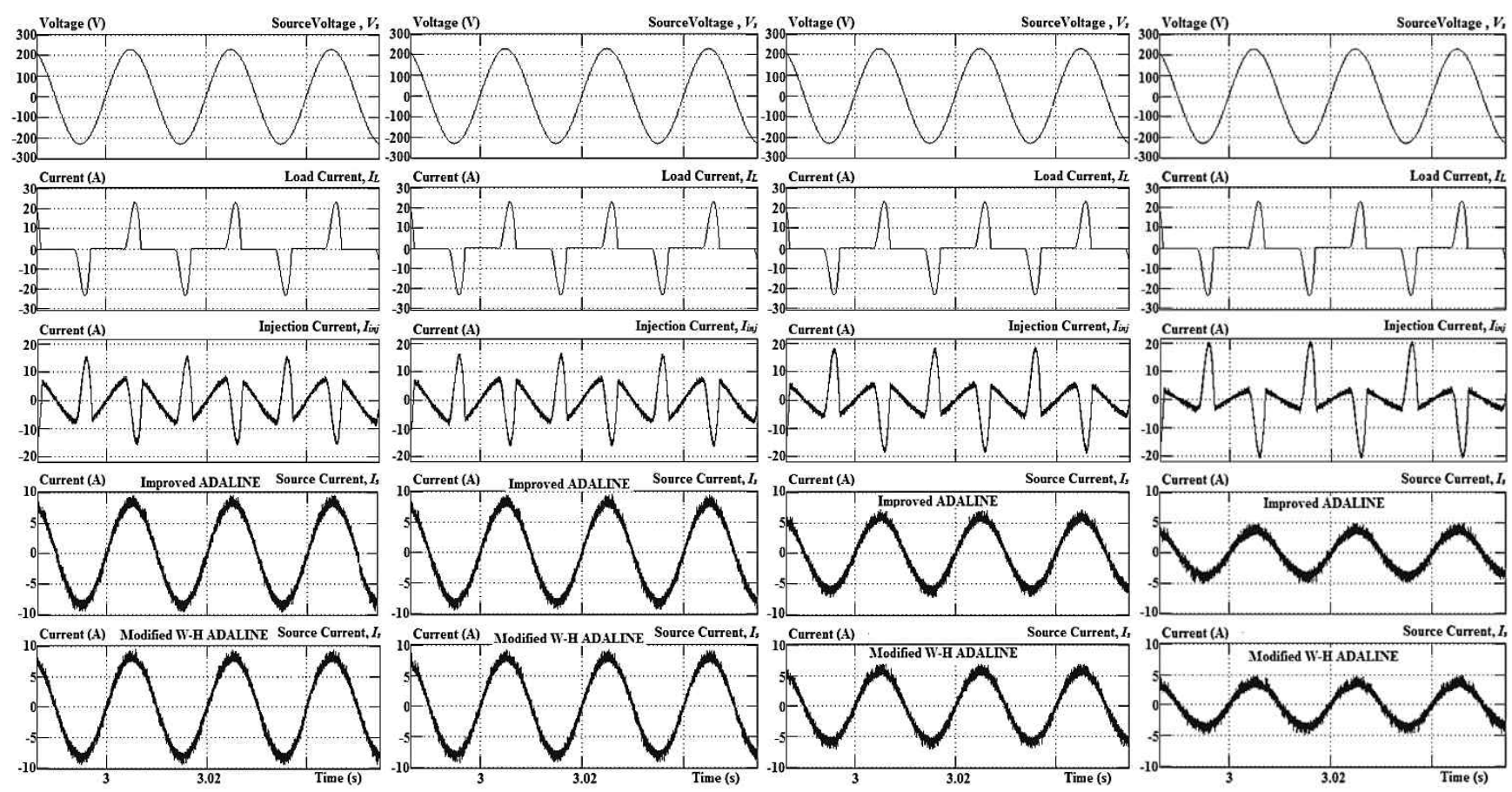

(a)
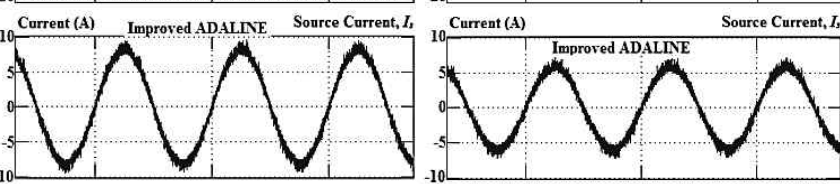

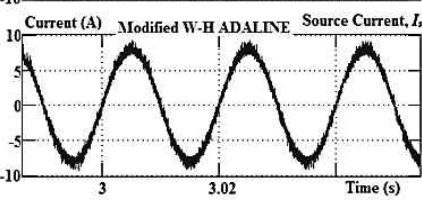

(b)

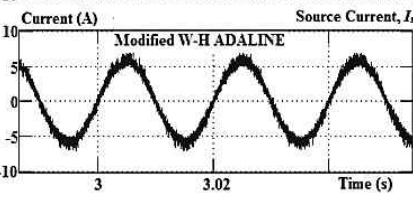

(c)

(d)

Fig. 7. Simulation results of steady state operation using capacitive load under different irradiance levels at (a) $0 \mathrm{~W} / \mathrm{m}^{2}$, (b) $200 \mathrm{~W} / \mathrm{m}^{2}$, (c) $600 \mathrm{~W} / \mathrm{m}^{2}$, and (d) $1000 \mathrm{~W} / \mathrm{m}^{2}$

$\mathrm{kW}$. From the data collected, both harmonics extraction algorithms are able to reduce the source power according to the irradiance level. The higher the irradiances, the higher percentage of source power reduction. However, the 

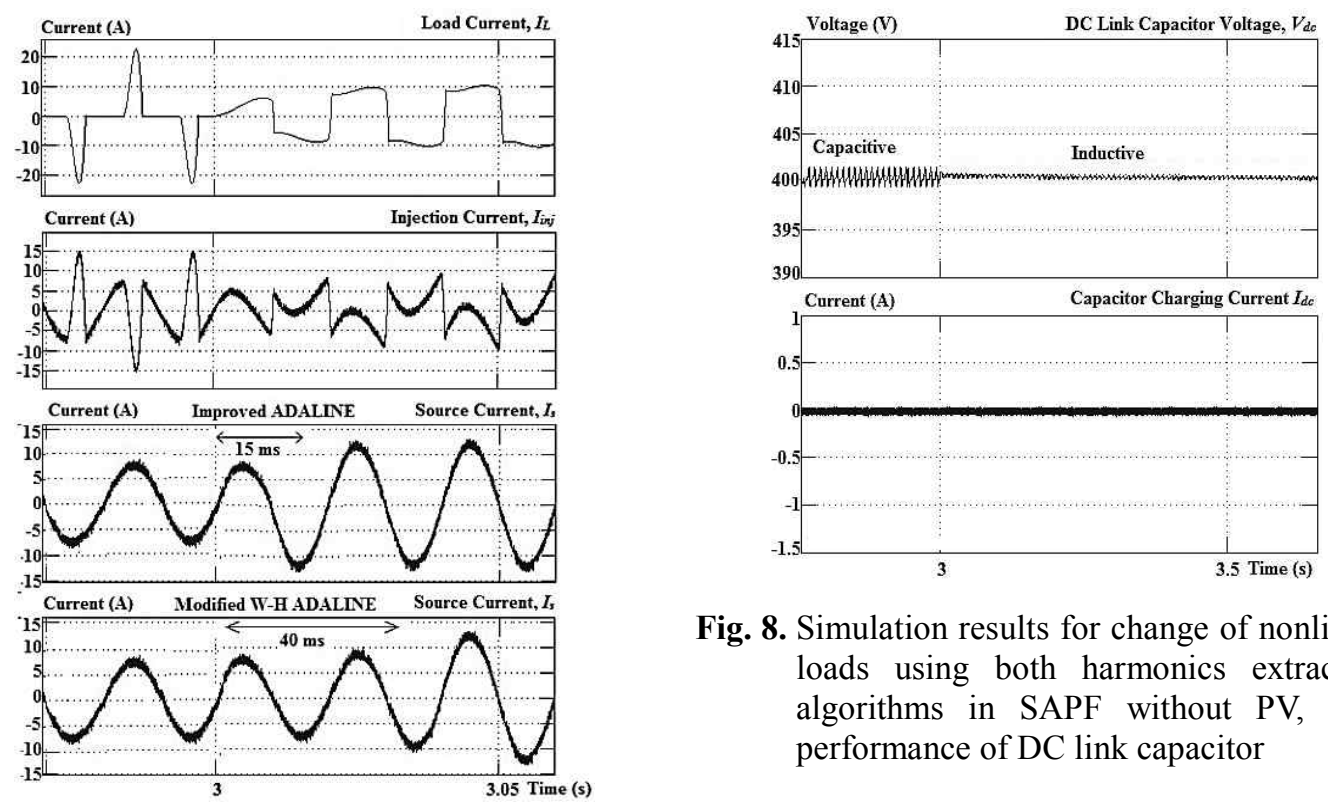

Fig. 8. Simulation results for change of nonlinear loads using both harmonics extraction algorithms in SAPF without PV, with performance of DC link capacitor
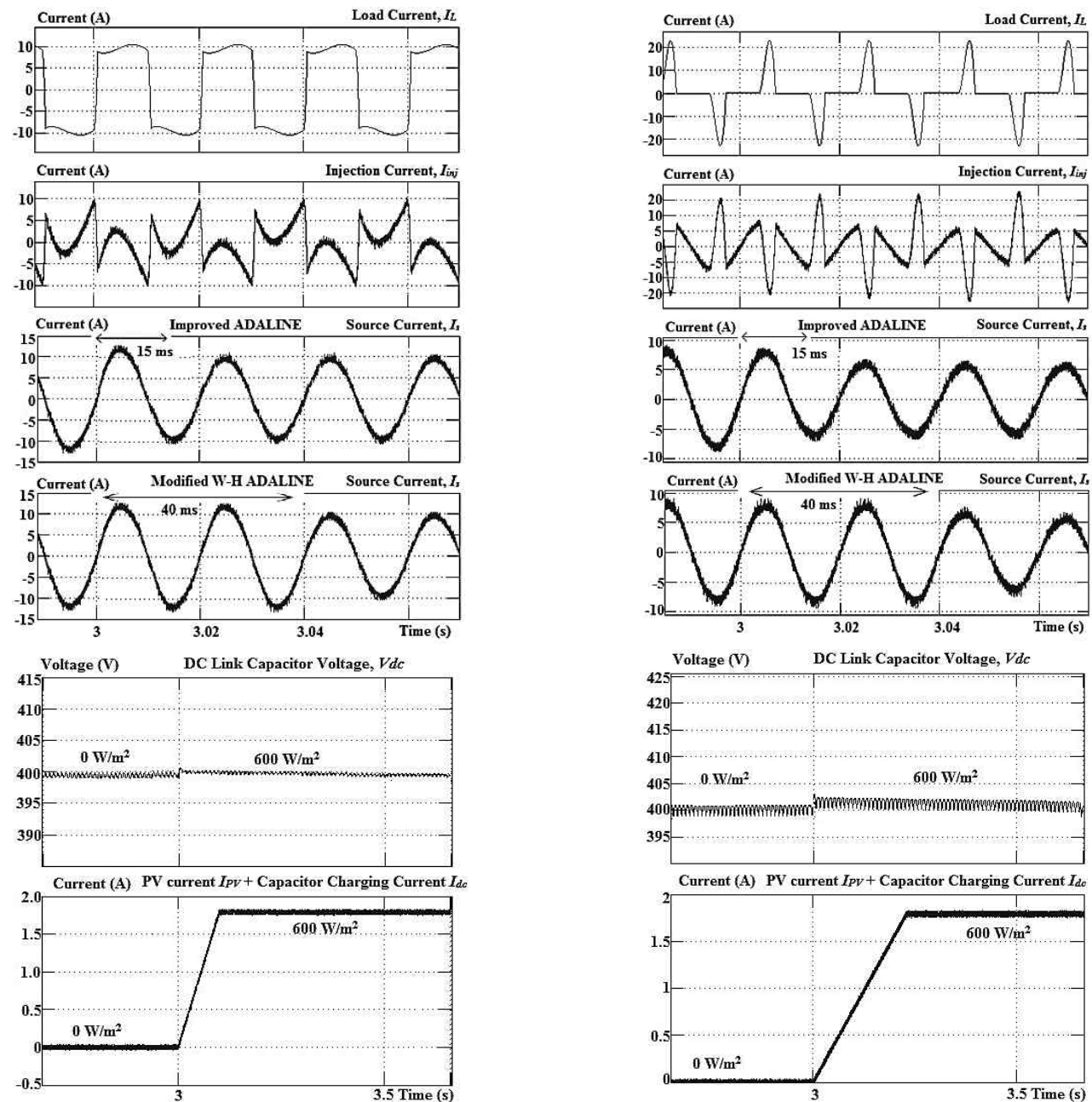

(a)

(b)

Fig. 9. Simulation results for off-on operation between PV and SAPF using both harmonics extraction algorithms, with performance of DC link capacitor performances, for (a) inductive and (b) capacitive loads 
Improved ADALINE Harmonics Extraction Algorithm for Boosting Performance of Photovoltaic Shunt Active Power Filter under

Table 5. Experimental results of the source power reduction and its percentage for Improved ADALINE algorithm.

\begin{tabular}{|c|c|c|c|c|c|c|c|c|}
\hline \multirow{2}{*}{ Parameter } & \multicolumn{4}{|c|}{ Inductive } & \multicolumn{4}{|c|}{ Capacitive } \\
\hline & $0 \mathrm{~W} / \mathrm{m}^{2}$ & $200 \mathrm{~W} / \mathrm{m}^{2}$ & $600 \mathrm{~W} / \mathrm{m}^{2}$ & $1000 \mathrm{~W} / \mathrm{m}^{2}$ & $0 \mathrm{~W} / \mathrm{m}^{2}$ & $200 \mathrm{~W} / \mathrm{m}^{2}$ & $600 \mathrm{~W} / \mathrm{m}^{2}$ & $1000 \mathrm{~W} / \mathrm{m}^{2}$ \\
\hline Source power reduction (W) & 0.00 & 23 & 66 & 110 & 0.00 & 16 & 48 & 82 \\
\hline Percentage of source power reduction (\%) & 0.00 & 5.11 & 14.66 & 24.44 & 0.00 & 4.21 & 12.63 & 21.58 \\
\hline
\end{tabular}
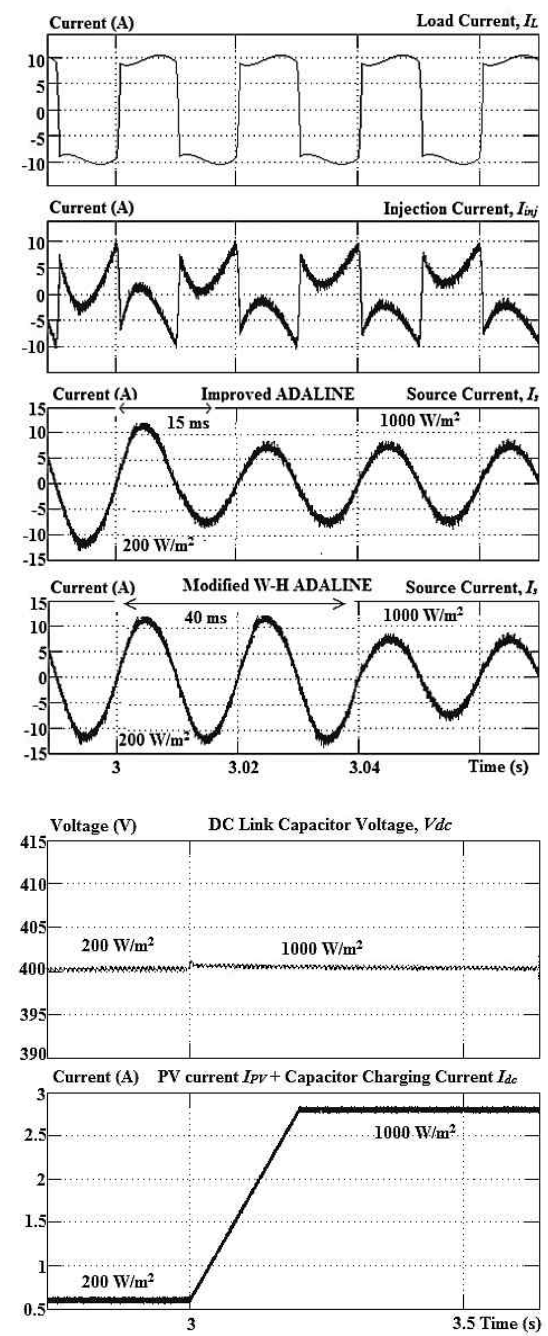

(a)
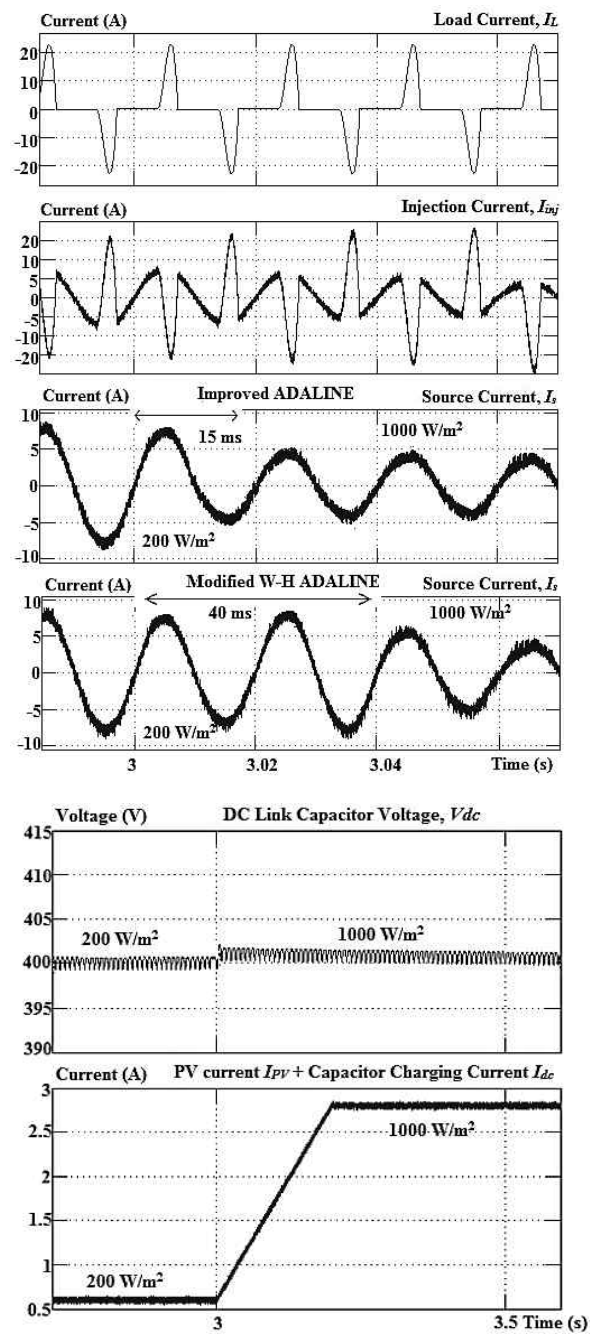

(b)

Fig. 10. Simulation results for change of irradiances using both harmonics extraction algorithms, with performance of DC link capacitor, for (a) inductive and (b) capacitive loads

proposed algorithm reduces the source power higher which directly gives high percentage of source power reduction as compared to the existing algorithm. Accurate injection current produced due to effectiveness of the proposed algorithm mainly contributes to this achievement. According to Eq. 11, accurate harmonic extraction leads to higher accuracy of injection current which will result better mitigation of the harmonics. Subsequently, lower THD values of the source current are obtained.

For the first dynamic operation, performances of both harmonics extraction algorithms during change of nonlinear loads are shown in Fig. 8. The proposed algorithm performs with response time of only $15 \mathrm{~ms}$, as compared to the existing algorithm which needs $40 \mathrm{~ms}$. Meanwhile, Fig. 9 shows the results obtained during off-on operation of PV by using both nonlinear loads, and Fig. 10 shows the results obtained for change of irradiances, also using both nonlinear loads. From Figs. 9 and 10, the response time taken by the proposed algorithm is also in about $15 \mathrm{~ms}$ only, but for the existing algorithm, it takes about $40 \mathrm{~ms}$. In overall, significantly, the results show the proposed algorithm has produced faster response times in all testing conditions as compared to the existing algorithm.

Performances of DC link capacitor are also observed, as 
shown in Figs. 8 to 10. According to Fig. 8, during change of nonlinear loads, voltage of the DC link capacitor is appropriately controlled at $400 \mathrm{~V}_{\mathrm{dc}}$ with low overshoot within $1 \mathrm{~V}_{\mathrm{dc}}$ and fast response time $(0.1 \mathrm{~s})$. During this dynamic operation, the PV is not connected which lets the SAPF to operate with charging capacitor current $\mathrm{I}_{\mathrm{dc}}$ only. If no overshoot or undershoot occurs, definitely $\mathrm{I}_{\mathrm{dc}}$ will become zero. Different scenario happens when PV is connected with SAPF, in which the PV current IPV is produced, and as mentioned earlier, it is added to the charging capacitor current $\mathrm{I}_{\mathrm{dc}}$. According to Figs. 9 and 10, voltage of the DC link is successfully controlled with low

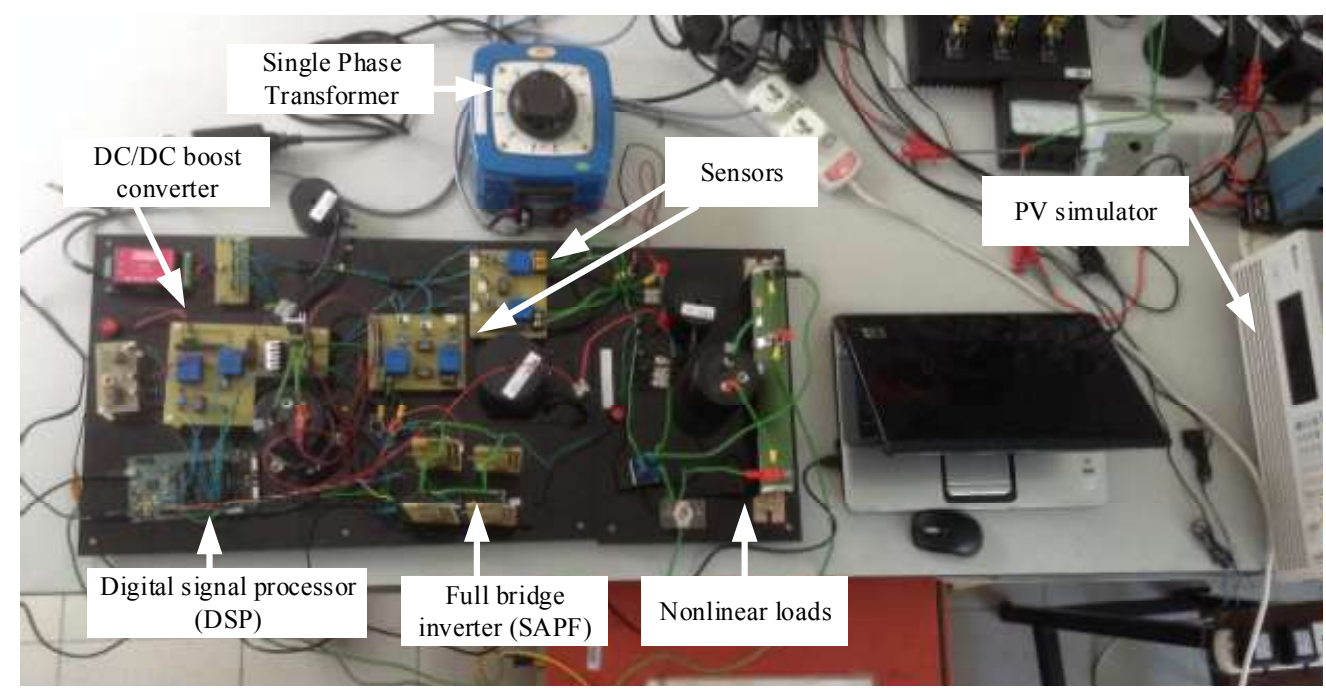

Fig. 11. Experimental prototype of single phase photovoltaic shunt active power filter

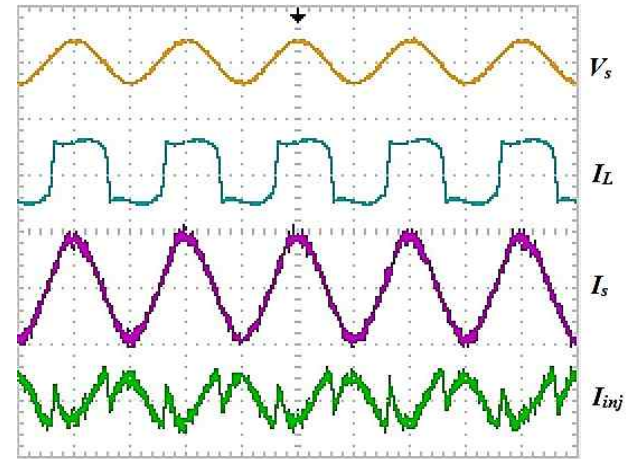

(a)

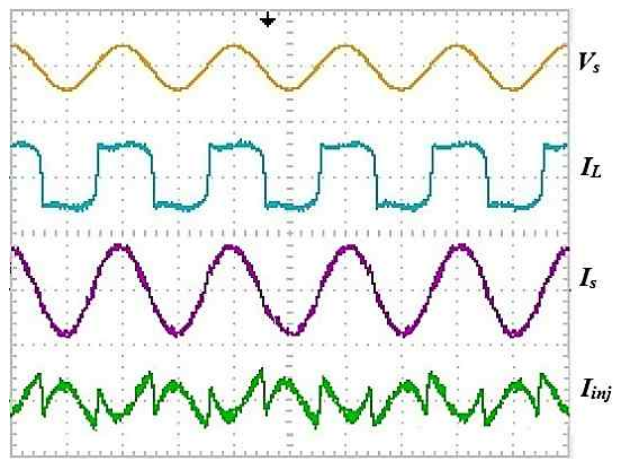

(b)

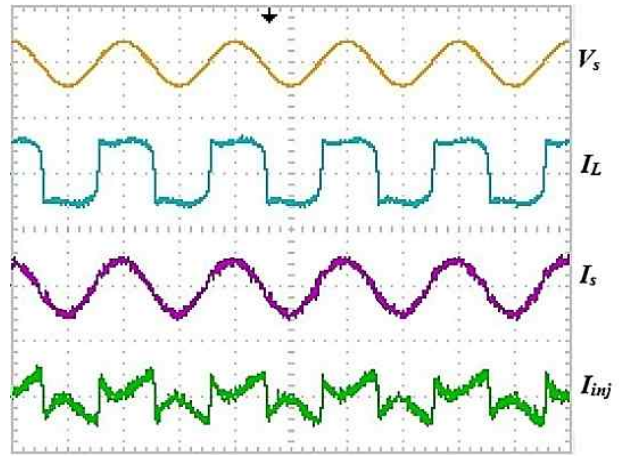

(c)

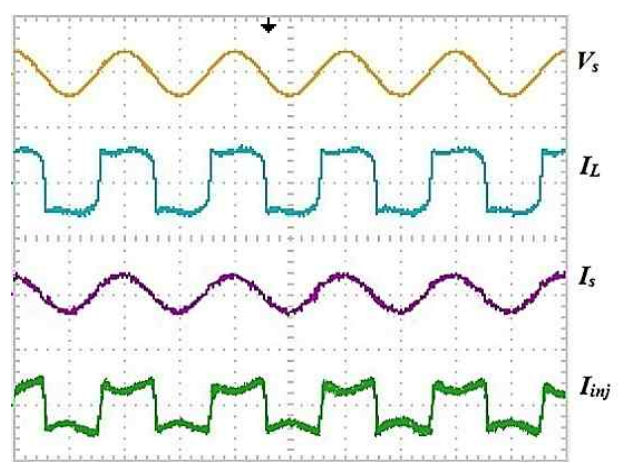

(d)

Fig. 12. Experimental results obtained using Improved ADALINE algorithm in steady state operation for inductive load which cover the voltage source $V_{s}(200 \mathrm{~V} / \mathrm{div})$, the load current $I_{\mathrm{L}}(5 \mathrm{~A} / \mathrm{div})$, the injection current $I_{\text {inj }}(5 \mathrm{~A} / \mathrm{div})$ and the source current $I_{\mathrm{S}}(5 \mathrm{~A} / \mathrm{div})$ at (a) $0 \mathrm{~W} / \mathrm{m}^{2}$, (b) $200 \mathrm{~W} / \mathrm{m}^{2}$, (c) $600 \mathrm{~W} / \mathrm{m}^{2}$, and (d) $1000 \mathrm{~W} / \mathrm{m}^{2}$ 
overshoot within $1.5 \mathrm{~V}_{\mathrm{dc}}$ and fast response time $(0.2 \mathrm{~s})$ for both nonlinear loads.

Meanwhile, maximum power produced by $\mathrm{PV}$ is also measured. Ideally, expected maximum powers for irradiances of $200 \mathrm{~W} / \mathrm{m}^{2}, 600 \mathrm{~W} / \mathrm{m}^{2}$ and $1000 \mathrm{~W} / \mathrm{m}^{2}$ are $260 \mathrm{~W}, 810 \mathrm{~W}$ and $1080 \mathrm{~W}$ respectively. By using Adaptive P\&O-Fuzzy MPPT algorithm, the maximum powers achieved for $1000 \mathrm{~W} / \mathrm{m}^{2}$ is $1072 \mathrm{~W}(99 \%$ of the ideal maximum power). For $600 \mathrm{~W} / \mathrm{m}^{2}$, the maximum power is $760 \mathrm{~W}(93 \%)$, and for $200 \mathrm{~W} / \mathrm{m}^{2}$, the maximum power is $240 \mathrm{~W}(93 \%)$. The obtained results show that the MPPT algorithm works well with efficiency above than $90 \%$ for all levels of irradiance.

\subsection{Experimental results}

Hardware prototype of the SAPF was developed as shown in Fig. 11 to test and to verify the proposed harmonics extraction algorithm. The PV simulator (CHROMA 62100H-600S) was used as a PV source by implementing characteristics of PV module SHARP NT180U1. The prototype used same load configurations as in the simulation work with voltage source of $100 \mathrm{~V}_{\mathrm{ac}}$ and the DC link capacitor voltage was set to $200 \mathrm{~V}_{\mathrm{dc}}$. Digital Signal Processor (DSP) TMS320F28335 was used to implement all the algorithms. As same as in the simulation work, the same steady state and dynamic operations were performed. However, only the proposed harmonics extraction algorithm was performed as to validate its practicality. For the steady state operation, Figs. 12 and 13 show the experimental results of the Improved ADALINE algorithm performed with multiple irradiance levels using inductive and capacitive loads respectively. Without PV (as shown in Figs. 12(a) and 13(a)), the proposed harmonics extraction algorithm produces THD values around $2.3 \%$ for inductive load and $2.8 \%$ for capacitive load. At $200 \mathrm{~W} / \mathrm{m} 2$ irradiance level, the THD values produced are $2.54 \%$ for inductive load and $3.15 \%$ for capacitive load. Meanwhile, at $600 \mathrm{~W} / \mathrm{m} 2$ irradiances, the THD values obtained are $2.8 \%$ and $3.32 \%$ for inductive and capacitive loads respectively. Lastly, at $1000 \mathrm{~W} / \mathrm{m} 2$ irradiance, the proposed harmonics extraction algorithm performs with THD values of $3.2 \%$ for inductive load and $3.76 \%$ for capacitive load. The results in steady state operation prove that the Improved ADALINE algorithm works well with THD values below than $5 \%$ with any irradiance level for both nonlinear loads. Table 5 provides the overall experimental results for source power reduction and percentage of source power reduction using the Improved ADALINE algorithm for both nonlinear loads. The source powers PT at $0 \mathrm{~W} / \mathrm{m} 2$ irradiances (without PV) are $450 \mathrm{~W}$ for inductive load and $380 \mathrm{~W}$ for capacitive load. From Table 5, the Improved ADALINE algorithm does reducing the source power. The percentage of source power reduction is almost same as in

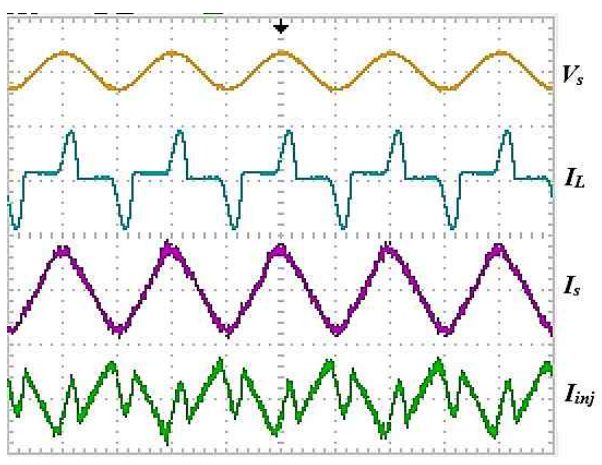

(a)

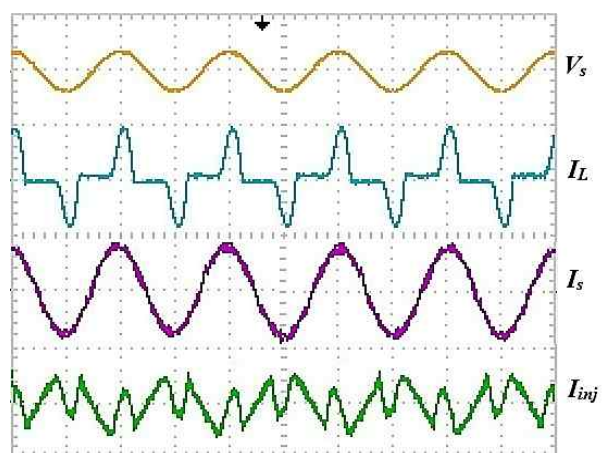

(b)

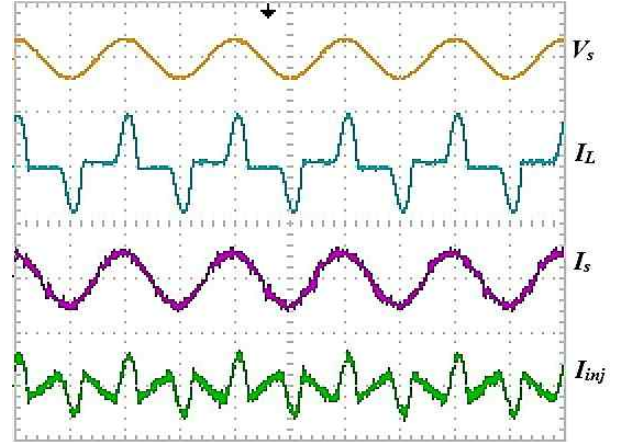

(c)

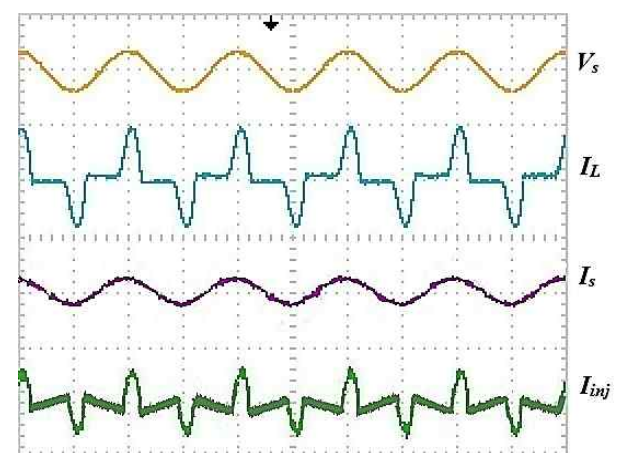

(d)

Fig. 13. Experimental results obtained using Improved ADALINE algorithm in steady state operation for capacitive load which cover the voltage source $V_{s}(200 \mathrm{~V} / \mathrm{div})$, the load current $I_{\mathrm{L}}(5 \mathrm{~A} / \mathrm{div})$, the injection current $I_{\text {inj }}(5 \mathrm{~A} / \mathrm{div})$ and the source current $I_{\mathrm{S}}(5 \mathrm{~A} / \mathrm{div})$ at (a) $0 \mathrm{~W} / \mathrm{m}^{2}$, (b) $200 \mathrm{~W} / \mathrm{m}^{2}$, (c) $600 \mathrm{~W} / \mathrm{m}^{2}$, and (d) $1000 \mathrm{~W} / \mathrm{m}^{2}$ 
the simulation work, thus showing that the Improved ADALINE algorithm is applicable in practical operation of SAPF.

The second test was focused to 3 types of dynamic operation. Fig. 14 shows the experimental results of the proposed harmonics extraction algorithm under change of nonlinear loads. During this dynamic operation, the proposed algorithm takes about $20 \mathrm{~ms}$ of response time to mitigate the current harmonics. Fig. 15 shows the experimental results of the proposed harmonics extraction algorithm under off-on operation between PV and SAPF using both nonlinear loads and lastly, Fig. 16 shows the experimental results of the proposed harmonics extraction algorithm under change of irradiances using both nonlinear loads. The proposed algorithm also takes about $20 \mathrm{~ms}$ of response time during both dynamic operations. The obtained results prove that the proposed harmonics extraction algorithm has consistently performed well with fast response time in all situations of dynamic operation.

For DC link capacitor, according to Fig. 14, its voltage is

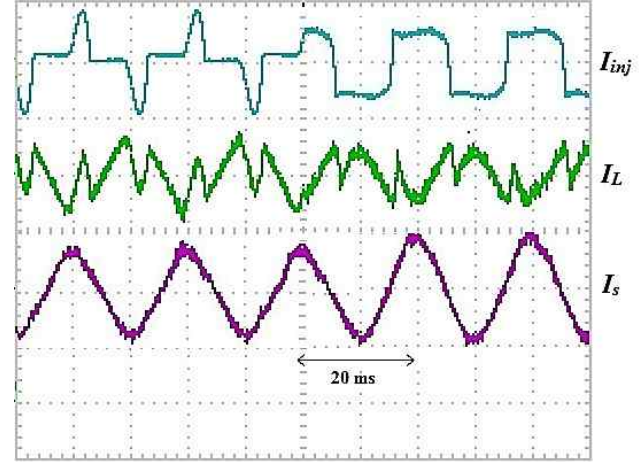

(a)

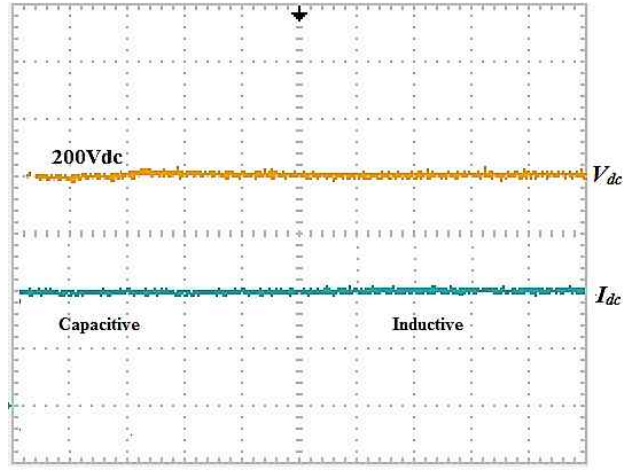

(b)

Fig. 14. Experimental results obtained using Improved ADALINE algorithm with (a) change of nonlinear loads which cover the load current $I_{\mathrm{L}}(5 \mathrm{~A} / \mathrm{div})$, the injection current $I_{\text {inj }}(5 \mathrm{~A} / \mathrm{div})$ and the source current $I_{\mathrm{S}}(5 \mathrm{~A} / \mathrm{div})$, and (b) performance of DC link capacitor

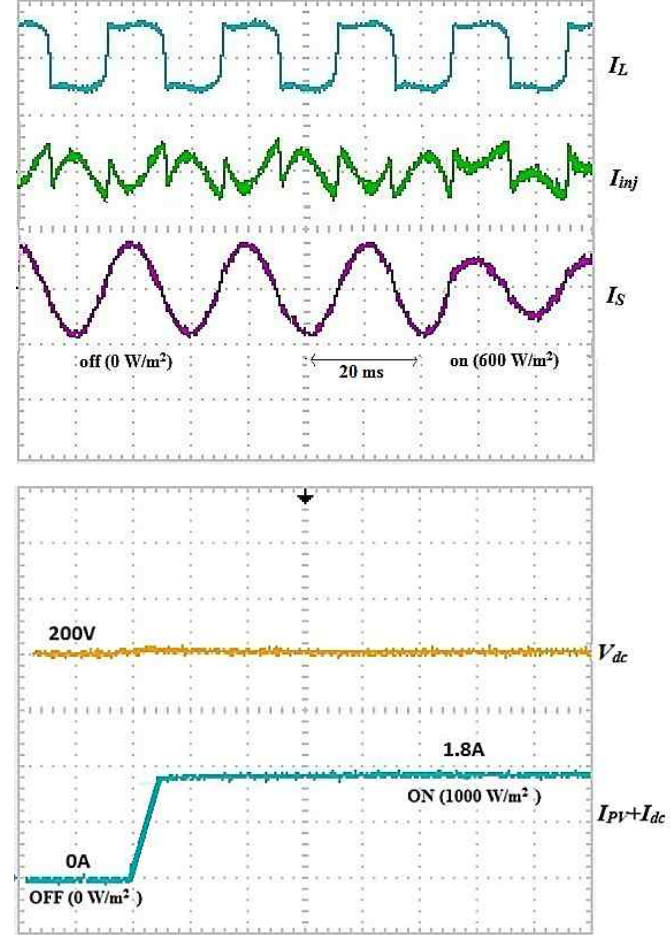

(a)

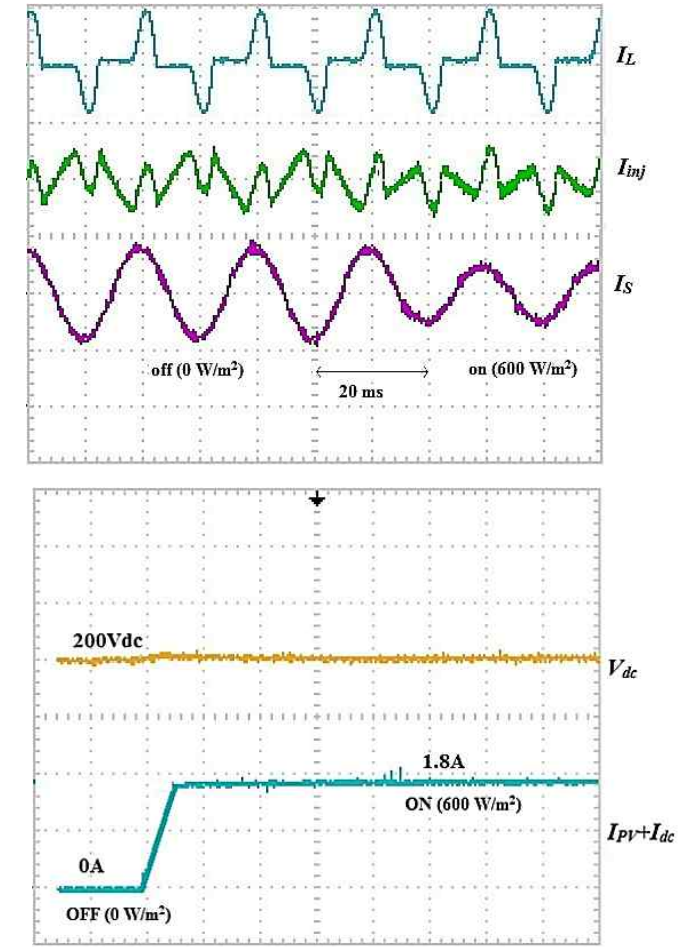

(b)

Fig. 15. Experimental results obtained using Improved ADALINE algorithm with off-on operation between PV and SAPF which cover the load current $I_{\mathrm{L}}(5 \mathrm{~A} / \mathrm{div})$, the injection current $I_{\text {inj }}(5 \mathrm{~A} / \mathrm{div})$ and the source current $I_{\mathrm{S}}(5 \mathrm{~A} / \mathrm{div})$ with its DC link capacitor performances for (a) inductive, and (b) capacitive loads 
properly controlled with low overshoot $\left(2 \mathrm{~V}_{\mathrm{dc}}\right)$ and fast response time $(0.1 \mathrm{~s})$. According to Figs. 15 and 16, with effect of PV, voltage of the DC link capacitor still can be controlled with low overshoot in within $2 \mathrm{~V}_{\mathrm{dc}}$ and fast response time $(0.1 \mathrm{~s}$ to $0.2 \mathrm{~s})$ under dynamic operations for both nonlinear loads. For performance of PV, as same as in the simulation work by providing three levels of irradiance, the expected maximum powers for $1000 \mathrm{~W} / \mathrm{m} 2$ is $540 \mathrm{~W}$, $600 \mathrm{~W} / \mathrm{m} 2$ is $400 \mathrm{~W}$, and $200 \mathrm{~W} / \mathrm{m} 2$ is $130 \mathrm{~W}$. Thus, by referring to Figs. 15 and 16, the achieved maximum powers are $536 \mathrm{~W}(99 \%)$ for $1000 \mathrm{~W} / \mathrm{m} 2,360 \mathrm{~W}(90 \%)$ for $600 \mathrm{~W} / \mathrm{m} 2$ and $120 \mathrm{~W}(92 \%)$ for $200 \mathrm{~W} / \mathrm{m} 2$ respectively. Both DC capacitor voltage and MPPT algorithms will ensure that voltage of the DC link capacitor is effectively controlled, and when dealing with change of irradiances, maximum power is delivered from PV with fast response time.

\section{Conclusion}

This paper has presented a significant contribution to improve performance of harmonics extraction algorithm, by having better approach known as Improved ADALINE algorithm. Its crucial role has been shown clearly with integration of PV with SAPF, especially on generating injection current to compensate harmonics at PCC. The
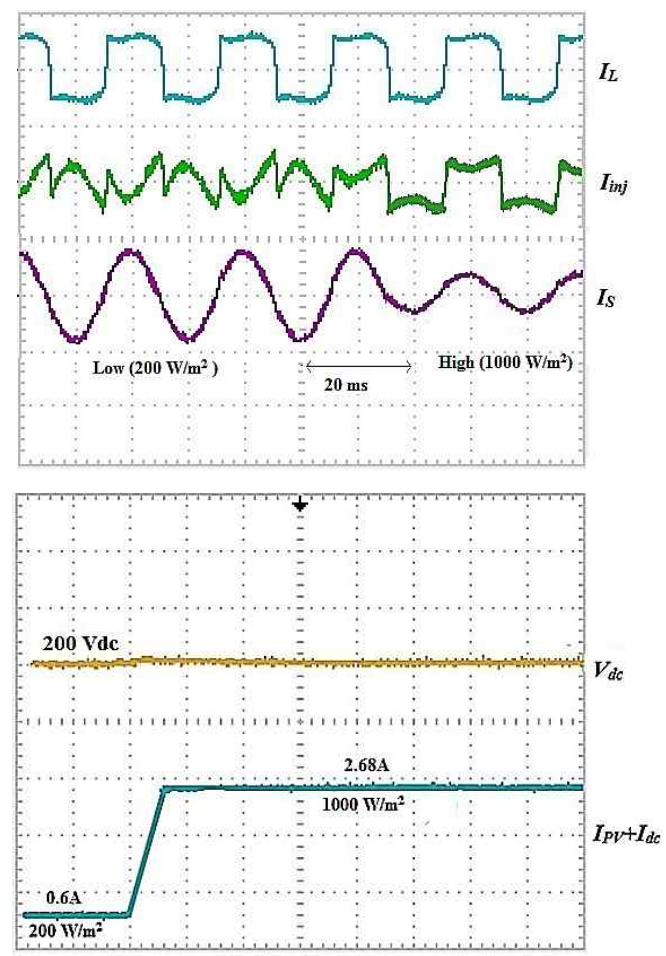

(a) proposed harmonics extraction algorithm has successfully performed well not only under steady state operation, but also 3 critical types of dynamic operation, with better achievement as compared to the Modified W-H ADALINE algorithm. Both simulation and experimental works have shown clearly that the proposed algorithm is able to achieve low THD values with both nonlinear loads and perform fast response time under all situations of dynamic operation. The obtained findings prove that the improved ADALINE algorithm shows the fastest convergence speed among ADALINE techniques used specifically for harmonics extraction. Subsequently, significant reduction of power supplied from the grid has been shown clearly in this work when PV is connected to SAPF.

\section{References}

[1] Y. Du, D.D. Lu, G.M.L. Chu, W. Xiao, "Closed-Form Solution of Time-Varying Model and Its Applications for Output Current Harmonics in Two-Stage PV Inverter", IEEE Transactions on Sustainable Energy, vol. 6, no. 1, pp. 142-150, 2015.

[2] H. Hu, Q. Shi, Z. He, J. He, S. Gao, "Potential Harmonic Resonance Impacts of PV Inverter Filters on Distribution Systems", IEEE Transactions on Sustainable Energy, vol. 6, no. 1, pp. 151-161, 2015.
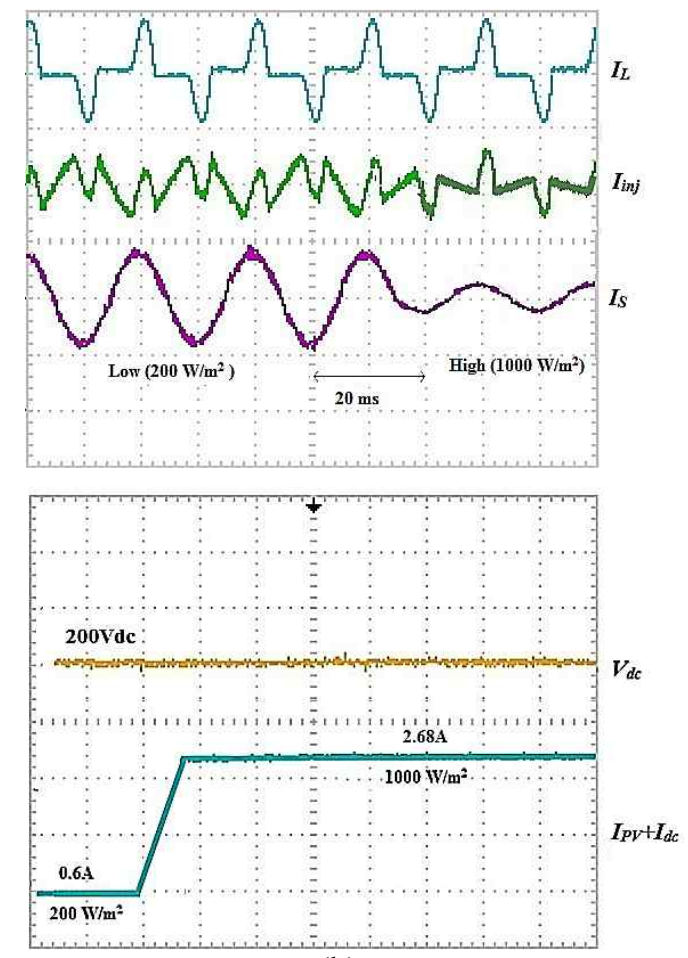

(b)

Fig. 16. Experimental results obtained using Improved ADALINE algorithm with change of irradiances which cover the load current $I_{\mathrm{L}}(5 \mathrm{~A} / \mathrm{div})$, the injection current $I_{\text {inj }}(5 \mathrm{~A} / \mathrm{div})$ and the source current $I_{\mathrm{S}}(5 \mathrm{~A} / \mathrm{div})$ its DC link capacitor performances for (a) inductive and (b) capacitive loads 
[3] He. Guofeng, Xu. Dehong, Chen, Min, "A Novel Control Strategy of Suppressing DC Current Injection to the Grid for Single-Phase PV Inverter", IEEE Transactions on Power Electronics, vol. 30, no. 3, pp. 1266-274, 2015.

[4] A.K. Al-Othman, M.E. AlSharidah, N.A. Ahmed, B.N. Alajmi, "Model Predictive Control for Shunt Active Power Filter in Synchronous Reference Frame", Journal of Electrical Enginering Technology, vol. 11, no. 2, pp. 405-415, 2016.

[5] R. Faranda, S. Leva, "Energy Comparison of MPPT Techniques for PV Systems", WSEAS transaction on power systems, vol. 3, pp. 446-455, 2008.

[6] IEEE Standard 519, "IEEE Recommended Practice and Requirements for Harmonic Control in Electric Power Systems", New York: Institute of Electrical and Electronics Engineers, pp. 1-29, 2014.

[7] H. Dogan, R. Akkaya, "A control scheme employing an adaptive hysteresis current controller and an uncomplicated reference current generator for a singlephase shunt active power filter", Turkish Journal of Electrical Engineering \& Computer Sciences, vol. 22, pp. 1085-1097, 2014.

[8] H. Akagi, Y. Kanazawa, A. Nabae, "Instantaneous reactive power compensators comprising switching devices without energy storage components", IEEE Transaction on Industry Applications, vol. 3, pp. 625630, 2008.

[9] S. Charles, and C. Vivekanandan, “An Efficient FPGA based Real-Time Implementation Shunt Active Power Filter for Current Harmonic Elimination and Reactive Power Compensation", Journal of Electrical Engineering Technology, vol. 10, no. 4, pp. 1655-1666, 2015.

[10] M.A.M. Radzi, N.A. Rahim, "Neural network and band-less hysteresis approach to control switched capacitor active power filter for reduction of harmonics", IEEE Transaction on Industrial Electronics, vol. 54, no. 5, pp. 1477-1484, 2009.

[11] M. Cirrincione, M. Pucci, and G. Vitale, "A singlephase DG generation unit with shunt active power filter capability by adaptive neural filtering", IEEE Transaction on Industrial Electronics, vol. 55, no. 5, pp. 2093-2110, 2008.

[12] M.A.A. Mohd Zainuri, M.A. Mohd Radzi, A.C. Soh, and N.A. Rahim, "Development of adaptive perturb and observe-fuzzy control maximum power point tracking for photovoltaic boost dc-dc converter", IET Renewable Power Generation, vol. 8 , no. 2, pp. 183194, 2014.

[13] M.A.A. Mohd Zainuri, M.A. Mohd Radzi, A.C. Soh, N. Mariun and N.A. Rahim, " DC-link capacitor voltage control for single-phase shunt active power filter with step size error cancellation in self-charging algorithm", IET Power Electronics, pp. 1-13, 2015.

[14] H. Daniyal, E. Lam, L.J. Borle, H.H. Iu, "Hysteresis, PI and Ramptime Current Control Techniques for
APF: An experimental comparison", IEEE Conferences on Industrial Electronics and Applications, pp. 2151-2156, 2011.

[15] N.F.A. Abdul Rahman, M.A.M. Radzi, N. Mariun, A. Che Soh, and N.A. Rahim, "Dual Function of Unified Adaptive Linear Neurons Based Fundamental Component Extraction Algorithm for Shunt Active Power Filter Operation", International Review of Electrical Engineering (IREE), vol. 10, pp. 544-552, 2015.

[16] P. D. Seema, H. P. Inamdar, and A. P. Vaidya, "Simulation Studies of Shunt Passive Harmonic Filters: Six Pulse Rectifier Load Power Factor Improvement and Harmonic Control", ACEEE International journal on Electrical and Power Engineering, vol. 2, no. 1, pp. $1-6,2011$.

[17] L.B. Garcia Campanhol, S.A. Oliveira da Silva, and A. Goedtel, "Application of shunt active power filter for harmonic reduction and reactive power com-pensation in three phase four-wire systems", IET Power Electronics, vol. 7, no. 11, pp. 2825-2836, 2014.

[18] M. Cirrincione, M. Pucci, and G. Vitale, "A singlephase DG generation unit with shunt active power filter capability by adaptive neural filtering," IEEE Transaction on Industrial Electronics, vol. 55, no. 5, pp. 2093-2110, 2008.

[19] B. Singh, V. Verma, and J. Solanki, "Neural networkbased selective compensation of current quality problems in distribution system," IEEE Transaction on Industrial Electronics, vol. 54, no. 1, pp. 53-60, 2007.

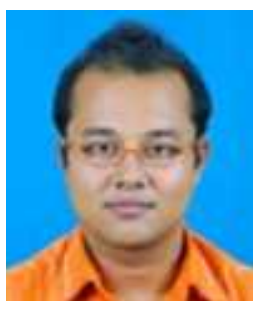

Muhammad Ammirrul Atiqi Mohd Zainuri was born in Kuala Lumpur, Malaysia, in 1988. He received his B.Eng. (Hons.) and his M.Sc. degree from Universiti Putra Malaysia (UPM), Serdang, Selangor, Malaysia. His research interests are photovoltaic, power electronics, power quality and Artificial Intelligent. He is currently pursuing his $\mathrm{PhD}$ at Department of Electrical and Electronic Engineering, Faculty of Engineering, Universiti Putra Malaysia.

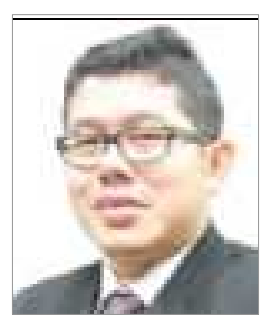

Mohd Amran Mohd Radzi was born in Kuala Lumpur, Malaysia, in 1978. He received his B.Eng. (Hons.) and his M.Sc. degree from Universiti Putra Malaysia (UPM), Serdang, Selangor, Malaysia, and his $\mathrm{PhD}$ degree in 2010 from University of Malaya. His research interests are power electronics, power quality and renewable energy. He is currently 
Associate Professor at Department of Electrical and Electronic Engineering, Faculty of Engineering, UPM, and Researcher at Centre for Advanced Power and Energy Research (CAPER), UPM.

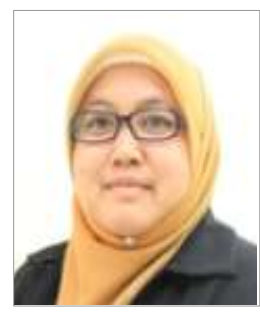

Azura Che Soh received her B.Eng. degree and M.Sc. in electrical and electronics engineering from Universiti Putra Malaysia (UPM), Malaysia in 1998 and 2002, respectively. She received the $\mathrm{PhD}$ degree in electrical engineering (major in control engineering) from Universiti Teknologi Malaysia. Her research interests include control system, intelligent control system, system modelling and energy management system. Currently, she is an Associate Professor at Department of Electrical and Electronic Engineering, Faculty of Engineering, UPM, and also Associate Researcher at Centre of Advanced Power and Energy Research (CAPER), UPM.

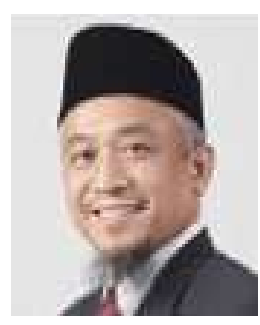

Norman Mariun received her B.Sc. degree in electrical and electronic engineering from University of Nottingham, Nottingham, U.K., in 1980, the M.Sc. in electrical and electronic engineering from North Carolina State University, Raleigh, NC, USA, in 1983, and the PhD degree from University of Bradford, Bradford, U.K., in 1998. His research interest include power system quality and energy management, power electronics application in power system, modeling and testing of semiconductor devices and application of multimedia in engineering education. Currently he is a Professor of electrical engineering with the Department of Electrical and Electronic Engineering, Faculty of Engineering, UPM, and also Head of research of Centre of Advanced Power and Energy Research (CAPER), UPM.

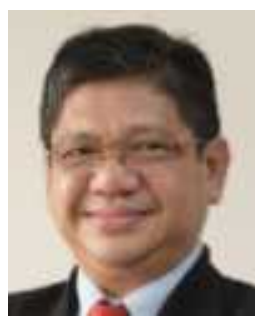

Nasrudin Abd. Rahim was born in Johor, Malaysia, in 1960. He received the B.Sc. (Hons.) and M.Sc. degree from the University of Strathclyde, Glasgow, U.K., and the PhD degree from Heriot-Watt University, Edinburgh, U.K. His research interests include power electronics, real-time control systems, and electrical drives. He is currently a Professor and the Director of the University of Malaya Power Energy Dedicated Advanced Centre (UMPEDAC), University of Malaya, Kuala Lumpur, Malaysia. He is also Adjunct Professor with King Abdul Aziz University, Jeddah, Saudi Arabia. 